\title{
$\left.\mathbf{C}^{-}\right\rceil \begin{aligned} & \text { CONGRESO } \\ & \text { INTERNACIONAL }\end{aligned}$
SOBRE \\ SOBRE \\ LF_O FOTOGRAFÍA
}

Congreso Internacional sobre Fotografía

UPV, 5 y 6 octubre 2017

Doi: http://dx.doi.org/10.4995/CIFo17.2017.6765

ISBN: 978-84-9048-604-7

\section{Sospechosos imaginarios: el retrato compuesto en el ámbito artístico por medio de los dispositivos fotográficos policiales.}

\section{Sergio Luna Lozano ${ }^{a}$}

âniversidad Politécnica de Valencia (serlulo@gmail.com)

\begin{abstract}
This paper traces a historical path through different devices, imaging devices or computer software used mainly by security forces to recreate the face of the criminal, investigating the proper functioning of these photographic devices and the evolution since its appearance as mechanical devices in the last quarter of the nineteenth century, until their digital conversion developed in the eighties of the last century. At the same time, we study a series of artistic projects based on the use of these devices for the construction of the photographic composite portrait, in which both their physical characteristics and their symbolic burden are exploited.
\end{abstract}

Keywords: Photography, portrait-robot, photographic devices, portrait, identity.

\begin{abstract}
Resumen
El presente artículo traza un recorrido histórico a través de diferentes aparatos, dispositivos de imagen o software informático usados principalmente por los cuerpos de seguridad para recrear el rostro del criminal, indagando en el propio funcionamiento de estos dispositivos fotográficos y en la evolución desde su aparición como aparatos mecánicos en el último cuarto del siglo XIX, hasta su conversión digital desarrollada en la década de los ochenta del pasado siglo. Paralelamente, se estudian una serie de proyectos artísticos basados en el uso de estos aparatos para la construcción del retrato compuesto fotográfico, en los cuales se explotan tanto sus características físicas como su carga simbólica.
\end{abstract}

Palabras clave: Fotografía, retrato-robot, dispositivos fotográficos, retrato, identidad. 
Sospechosos imaginarios: el retrato compuesto en el ámbito artístico por medio de los dispositivos fotográficos policiales. Imaginary suspects: the composite portrait in the artistic field by means of the police photographic devices.

\section{Introducción}

Desde su desarrollo en el último cuarto del s. XIX, el retrato compuesto fotográfico ha estado vinculado —entre otros propósitos - con el interés por descubrir el rostro genérico del criminal, y esta es una de las cuestiones que en sus inicios ocupó a Francis Galton (1822-1911), pionero en la práctica de la fotografía compuesta, un tipo de fotografía que evidenciaba a la perfección el positivismo de la época y que hacía visible a través de "una aparición puramente óptica del tipo criminal" (Sekula, 2003) las teorías estadísticas en torno a la herencia genética. Poco tiempo después de los primeros retratos compuestos realizados por Galton, surgió en Francia otro tipo de representación científica que sentaba las bases del retrato policial: la fotografía antropométrica, desarrollada por Alphonse Bertillon (1853-1914) en el seno de la Prefectura de Policía de Paris y destinada, a diferencia del retrato compuesto de Galton, a la creación de fichas descriptivas que permitieran la identificación del criminal.

Tanto en un caso como en otro, el uso de la fotografía como herramienta en el ámbito científico ha supuesto el desarrollo de nuevos dispositivos y sistemas fotográficos, que a la vez han dado lugar a otros aparatos de imagen que suponen una evolución de los sistemas originales. Estos nuevos aparatos destinados principalmente a un uso policial también han sido la base de distintos proyectos fotográficos artísticos.

\section{El retrato compuesto a través del promedio y la superposición de imágenes}

\subsection{Los experimentos de Francis Galton}

El retrato compuesto fue descrito por Francis Galton por primera vez en un ensayo publicado en 1878. En aquel discurso se trazaban las virtudes de este procedimiento fotográfico, así como sus posibles aplicaciones y los campos de estudio que iniciaba. Aunque el proceso básico consistía en obtener un rostro promediado a partir de un conjunto de retratos, proyectando sobre una misma placa sensibilizada las distintas imágenes durante un tiempo de exposición concreto — el tiempo normal de exposición dividido entre el número de retratos- (Fig. 1), Galton describe otros métodos para visualizar los retratos compuestos de distintos individuos a partir de dispositivos concebidos por él mismo, como el denominado prisma de doble imagen (Fig. 2). Según su impulsor, este sistema suponía el "mejor instrumento [...] ideado y utilizado hasta el momento" (Galton, 2006), consistiendo en un prisma de espato que permitía, a partir de dos fotografías, proyectar la "imagen normal de un componente [...] sobre la imagen extraordinaria del otro" (Galton, 2006), pudiendo visualizar a simple vista o con ayuda de una lente la imagen compuesta resultante. Más adelante Galton (2006) prosigue en su artículo:

"He experimentado con otros muchos mecanismos; de hecho, existen diversas formas de superponer ópticamente dos o más imágenes. He utilizado un sextante (con su telescopio acoplado) y también tiras de espejos dispuestas en diferentes ángulos para examinar simultáneamente sus distintos reflejos a través de un telescopio. [...] No he tenido la oportunidad de superponer imágenes disponiendo negativos de 
cristal en diferentes linternas mágicas, todas ellas proyectadas sobre la misma pantalla; pero este procedimiento, o incluso un simple aparato diorámico, sería muy adecuado para exhibir efectos de montaje ante un grupo de espectadores y, si se utilizara luz eléctrica para la iluminación, el efecto sobre la pantalla podría, a su vez, ser fotografiado".

A pesar de los experimentos desarrollados por el antropólogo, sin duda el método de mayor éxito a la hora de realizar compuestos, fue el procedimiento a partir de la sobreimpresión de negativos que hemos comentado, con el que promedió cientos de retratos de muy distintas procedencias y resultados.

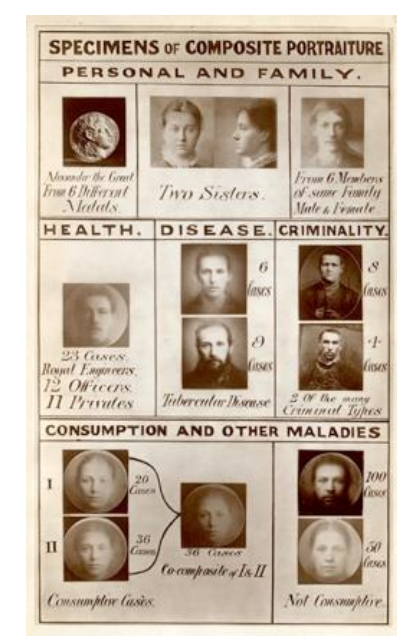

Fig. 1 Ejemplos de retrato compuesto (1983)

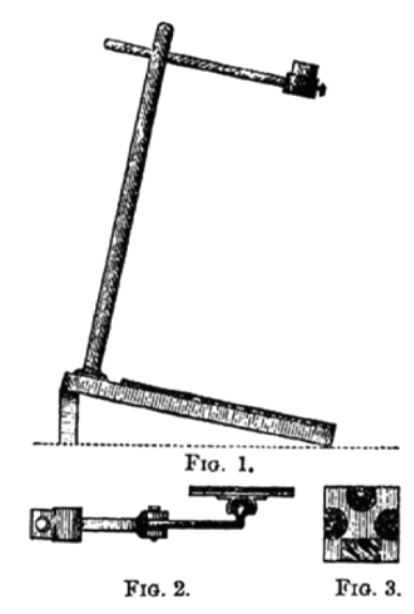

Fig. 2 Diagrama del prisma de doble imagen

\subsection{Minolta Montage Unit}

Un siglo más tarde de que Francis Galton ideara e imaginara estos instrumentos, surgió un dispositivo óptico que fue presentado en la feria Photokina de Colonia en 1972 y que, de algún modo, parece que adopte literalmente algunas de las características descritas por el antropólogo inglés. Se trata del Minolta Montage Unit (Fig. 3), un sintetizador desarrollado por Minolta Co. en Japón y fabricado en Alemania. Su sistema se compone de tres partes principalmente: un mezclador óptico, un circuito cerrado de televisión y un monitor de vídeo. El cuerpo principal del aparato lo ocupa el mezclador óptico, que permite la combinación de hasta cuatro imágenes para realizar el retrato compuesto. La imagen situada en la ranura inferior del aparato actúa como base del compuesto, del que podrán modificarse hasta tres rasgos a partir de las otras fotografías insertadas en las aberturas superiores. A través de distintos filtros de cristal se oscurecen y esconden partes de la imagen-base para reflejar los correspondientes fragmentos de las imágenes secundarias. La mezcla de estas fotografías es capturada por la cámara del circuito cerrado de televisión y visualizada a través del monitor de vídeo. Una vez la imagen resultante se muestra en la pantalla, se puede fotografiar para su positivado y reproducción.

A pesar de que el sintetizador ofrecía unos resultados bastante satisfactorios, ofreciendo una "imagen que da la apariencia de una cara real" (Duncan y Laughery, 1977), y que alcanzó bastante popularidad desde su comercialización, consagrándose junto al Identikit II y el Photofit como uno de los sistemas no computarizados para realizar compuestos más usados en Alemania, Japón y EE.UU., su producción y distribución conllevaba algunos inconvenientes. Para un empleo óptimo, era necesario contar con una colección de retratos de distintos 
Sospechosos imaginarios: el retrato compuesto en el ámbito artístico por medio de los dispositivos fotográficos policiales. Imaginary suspects: the composite portrait in the artistic field by means of the police photographic devices.

rasgos faciales que funcionasen como software para el dispositivo, y estas imágenes no se incluían en el sintetizador, pues como comentan Duncan y Laughery (1977), las fotografías que pudieran usarse en Japón no serían válidas para la construcción de caras americanas, por lo que la compilación de retratos habría que crearla ex profeso, teniendo en cuenta que para un correcto empleo del sintetizador los retratos habrían de tener similares características en cuanto a pose, iluminación o escala, a pesar de que la máquina era capaz de ajustar hasta cierto nivel el tamaño de las imágenes secundarias, así como el brillo y el contraste.

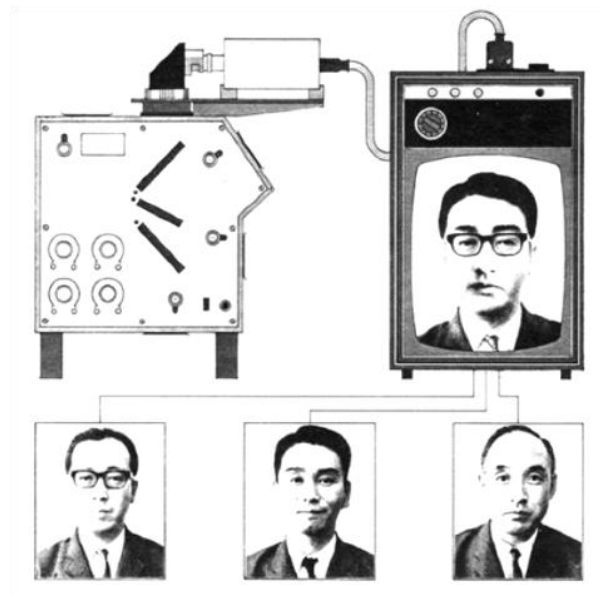

Fig. 3 Diagrama del Minolta Montage Unit

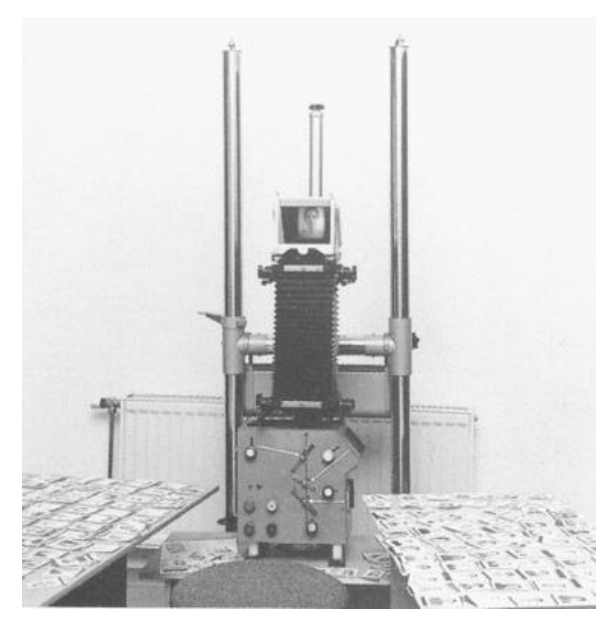

Fig. 4 Fotografia del Minolta Montage Unit

Si el propósito de Galton con la superposición de imágenes y el promedio iba enfocado a la búsqueda del tipo, esa "figura imaginaria que posee los rasgos medios de un determinado grupo de hombres" (Galton, 2006), a partir de varios grupos sociales, la finalidad de la Minolta Montage Unit fue muy distinta. Parece que en un principio el sintetizador estaba orientado a la simulación de reconstrucciones faciales quirúrgicas, cuestión que cobra sentido si pensamos que fue desarrollado en Japón y solamente habían pasado unas tres décadas desde el ataque nuclear de Hiroshima y Nagasaki. Pero pronto las fuerzas policiales germanas vieron en este aparato el potencial para la recreación del rostro de un sospechoso a partir de descripciones de testigos, adquiriendo la policía de Düsseldorf el último ejemplar disponible en 1975, antes del cese de la producción por falta de ventas. (Erfolg mit Fratzen, 1978).

\subsection{Andere Porträts de Thomas Ruff}

El uso del sintetizador Minolta por parte de la policía se alargó hasta comienzos de los años noventa, donde probablemente las pocas unidades que quedasen acabarían olvidadas en algún almacén o expuestas al público en algún museo, como la que se conservaba en la Colección Histórica de la Policía de Berlín (Fig. 4), que años más tarde fue prestada al fotógrafo alemán Thomas Ruff para trabajar en la serie de trabajos denominada Andere Porträts (“Otros Retratos"), una serie basada en retratos compuestos a partir de dos imágenes. Ruff, que no tuvo acceso al archivo de rostros que la policía alemana había compilado durante años, tuvo que utilizar como base 
de datos que alimentase la unidad Minolta, material fotográfico producido anteriormente en la década de los ochenta en la serie Porträts ("Retratos") —uno de sus trabajos más conocidos— realizada a través de fotografías de gente cercana y compañeros de la Academia de Bellas Artes de Düsseldorf donde estudiaba. Las fotografías que conforman Porträts resultaron idóneas para incorporarlas al sintetizador, ya que en ellas se adopta una estética cercana a la de las fotos de pasaporte, en las que se siguen unas pautas rigurosas en cuanto a pose, encuadre, expresión... (Fig. 5) Si bien en los retratos más tempranos de la serie existe cierta flexibilidad en la posición de los sujetos, utilizando poses frontales, de perfil y en tres cuartos, conforme avanza el trabajo la frontalidad y la simetría de las imágenes es más rigurosa. En algunos de los compuestos generados en Andere Porträts (Fig. 6) se puede adivinar qué retratos han sido utilizados para su construcción, pues son reconocibles distintos rasgos o partes de las imágenes originales, aunque la apariencia final quede alterada, representada en forma de "retratos virtuales, rostros de personas que no existen" (Blank y Ruff, 2004).

En Porträts los modelos son identificados en el título de cada fotografía con la inicial del nombre y el primer apellido, aunque el carácter serial y repetitivo —en referencia al aparato burocrático - convierte estos sujetos en objetos (Adler, 2016) potenciando el anonimato de los individuos representados. En Andere Porträts este anonimato es todavía más patente, no quedando ningún registro de la identidad de los personajes y reduciendo el título de cada fotografía a un código numérico, como si de un fichero se tratase. Frente a los primeros retratos neutros e inexpresivos donde se produce cierta hiperobjetividad, estas imágenes resultan más subjetivas por el hecho de haber sido modeladas. Unas imágenes en las que se produce una doble construcción, la de la identidad del sujeto inventado y la de la propia imagen, que adopta un nuevo estado alejado del convencional, al tratarse de imágenes de imágenes, o dicho de otro modo, de fotografías compuestas por fotografías. Recordemos que el sintetizador muestra la imagen procesada a través de un monitor de vídeo, que habrá que fotografiar para materializar la imagen. En este caso, Ruff optó por producir las fotografías mediante serigrafías monocromas, en una posible referencia a las propias imágenes compuestas de sospechosos mostradas en los periódicos en los que, proporcionalmente más amplio, se aprecia la trama de la impresión característica de este medio impreso.

Thomas Ruff presentó Andere Porträts junto a una serie de visores estereoscópicos titulada 3D-Schwarzwald (“3D-Selva Negra") en la Bienal de Venecia de 1995, pero es preciso comentar que hubo un fotógrafo —aunque con menos repercusión - que ya había realizado una serie de retratos compuestos utilizando la Minolta Montage Unit. Se trata del artista alemán Clemens Mitscher y la serie Opfer ("Victimas") de 1987. La principal diferencia entre ambos trabajos, además de que Ruff usara un archivo fotográfico personal reinterpretando sus propias imágenes, es que en las composiciones de Mitscher casi no se notan las uniones entre los distintos rostros que conforman el retrato compuesto (Fig. 7), es decir, no existen apenas saltos entre las imágenes. Precisamente éste era un aspecto que Thomas Ruff quería evidenciar, afirmando que usó "una vieja técnica analógica porque era bastante brusca" en vez de una computadora cuya "manipulación resultante habría sido perfecta" (Blank y Ruff, 2004). 
Sospechosos imaginarios: el retrato compuesto en el ámbito artístico por medio de los dispositivos fotográficos policiales. Imaginary suspects: the composite portrait in the artistic field by means of the police photographic devices.

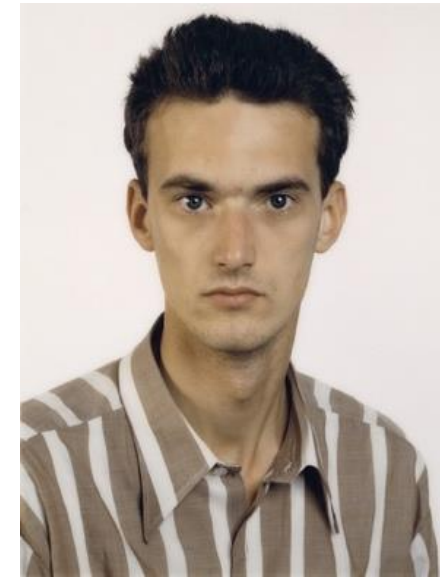

Fig. 5 Thomas Ruff, Porträts

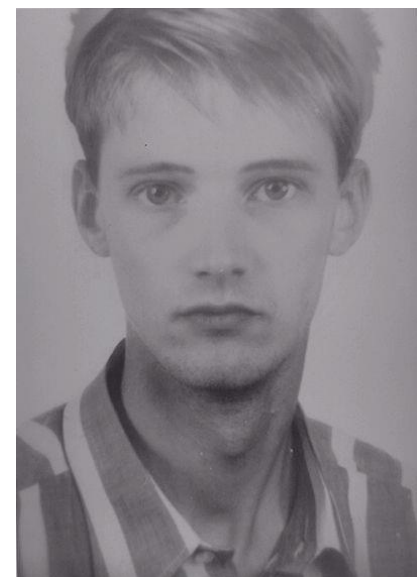

Fig.6 Thomas Ruff, Andere Porträts

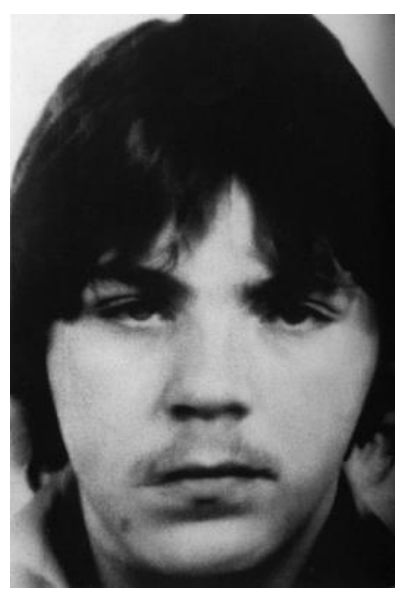

Fig. 7 Clemens Mitscher, Opfer

\section{El retrato compuesto a partir de los fragmentos del rostro}

\subsection{La antropometría judicial de Alphonse Bertillon}

Paralelamente al retrato compuesto de Galton surgió en Francia otro tipo de retrato científico, alejado de cualquier pretensión estética, con el propósito de facilitar la identificación de criminales reincidentes a través de la antropometría y la fotografía. El origen de este sistema — denominado a veces como bertillonage - surge cuando su impulsor Alphonse Bertillon al cortar distintos retratos fotográficos de criminales y yuxtaponer sus rasgos pudo comprobar que no encajaban perfectamente, cuestionándose la idea de que no existen dos individuos exactamente iguales, pues invariablemente aparecen diferencias minuciosas de tamaño, forma, color o textura que distinguen sus partes del cuerpo (Maxwell, 2010). Como buen conocedor de la estadística —su padre y hermano eran estadísticos- Bertillon piensa que tomando las medidas pertinentes de distintas partes del cuerpo de cualquier individuo, podría desarrollar un sistema de identificación bastante preciso (Maxwell, 2010) que permitiese reconocer a cualquier criminal fichado por la policía, independientemente de que modificase su aspecto físico, basándose en la creencia de que existen zonas corporales que permanecen inmutables con el tiempo a partir de cierta edad. Este sistema, presentado en fichas de identificación (Fig. 8), se componía principalmente de tres piezas: una fotografía, una descripción y una parte antropométrica. El tipo de fotografía empleada se correspondía con un doble retrato fotográfico de frente y perfil denominado retrato judicial, ejecutado bajo las precisas instrucciones de Bertillon, con el fin de estandarizar este tipo de retrato y evitar — en la medida de lo posible - cualquier fallo que pudiera ocasionar un mal uso de la posición y la iluminación del individuo a la hora de realizar las fotografías. Por otro lado, se tomaba una serie de medidas antropométricas correspondientes con distintas partes del cuerpo y el rostro que quedaban anotadas junto al doble retrato. La ficha finalmente se completaba con una descripción morfológica denominada portrait parlé, que consistía en una "descripción minuciosa de un individuo hecha especialmente en vista de su investigación e identificación en la vía pública" (Bertillon, 1893), es decir, una descripción verbal de las características físicas del sujeto. Este 
retrato verbal se redactaba con los "términos apropiados" (Bertillon, 1893) utilizando una serie de abreviaturas que optimizaban y agilizaban su escritura y confección. Por lo que, como expone Anne Maxwell (2010), "Bertillon creía que las descripciones más útiles de los criminales estaban compuestas de palabras", pues era importante "no mirar la cara como un todo, sino en sus partes separadas" (Maxwell, 2010). Es por ello que desarrolla una serie de cuadros sinópticos (Fig. 9) con todo un mapa desglosado de rasgos fisonómicos para el estudio del portrait parlé, que permitiesen la correcta aplicación del mismo. Estos archivos de rasgos faciales se componían de distintas categorías, como frente, orejas, nariz, mentón, cejas, etc. A pesar de que el principal uso del sistema de Bertillon fue el de capturar a criminales reincidentes, se creaba por otro lado un atlas del tipo criminal, incrementando "la capacidad del Estado moderno para disciplinar y controlar a sus sujetos" (Maxwell, 2010) a través del potencial documental y de registro de la fotografía.

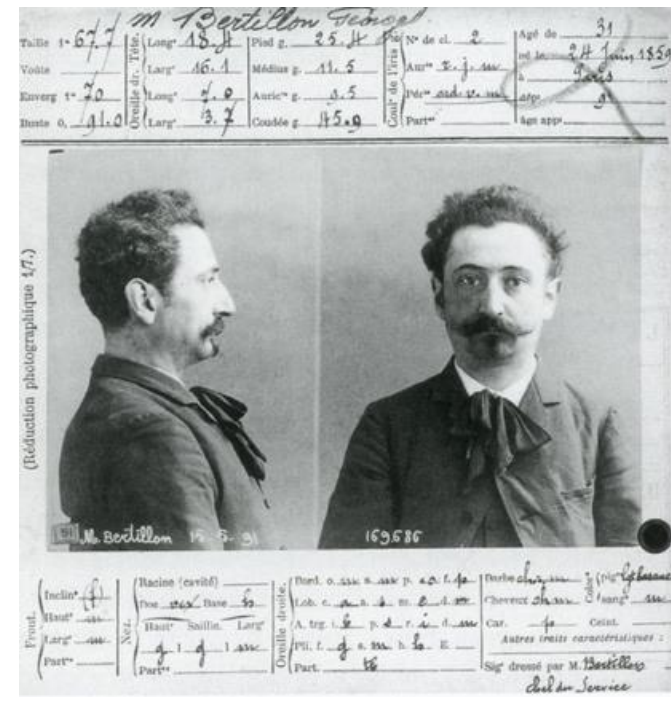

Fig. 8 Ficha descriptiva, Alphonse Bertillon

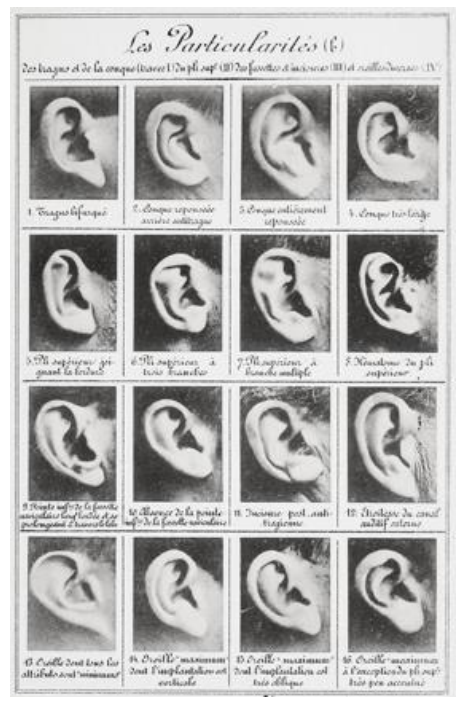

Fig. 9 Cuadro sinóptico de rasgos fisonómicos

\subsection{El Photo-FIT de Jacques Penry}

Aunque si bien Bertillon cuenta con todos los elementos para crearlo, no podemos hablar de retrato compuesto como tal en su caso, pues en ningún momento utiliza las imágenes parciales de los rostros para recrear otra cara nиeva. Pero su método es sin duda la base para distintos sistemas posteriores ideados principalmente para la identificación de criminales a partir del retrato compuesto. Destaca sin duda el sistema materializado por el topógrafo facial Jacques Penry en 1970. Denominado Photo-FIT ("Photo Facial Identification Technique"), este sistema consistía en un kit para realizar retratos compuestos — a modo de puzzle — a partir de fotografias de distintas secciones faciales (Fig. 10). Gracias a la cooperación con la policía británica, Penry tuvo acceso a sus archivos fotográficos, que le sirvieron como base para construir una amplía colección de rasgos faciales seleccionados de distintas fotografías (Penry 1970). Por aquel entonces, el kit se componía de 162 pares de ojos, 151 narices, 159 bocas, 112 mentones y mejillas y 261 frentes, con variaciones de bigotes, barbas, gafas y sombreros (Hopper, 1973), permitiendo recrear mediante su combinación una ingente cantidad de rostros frontales. En la primera versión ejecutada por Penry, la colección de facciones no incluía a mujeres ni a otros 
Sospechosos imaginarios: el retrato compuesto en el ámbito artístico por medio de los dispositivos fotográficos policiales. Imaginary suspects: the composite portrait in the artistic field by means of the police photographic devices.

grupos étnicos distintos a individuos masculinos "normalmente encontrados en el Reino Unido" (Penry 1970) lo que, a saber, incorporaría en futuras versiones tipos faciales afro-asiáticos y caucásicos, rasgos femeninos y rostros de perfil. El sistema era aparentemente sencillo: por un lado constaba de un índice visual que contenía miniaturas de los distintos rasgos de los que se componía el kit clasificados por tipos, además de una lámina con todas las formas de cara con los distintos modelos de pelo y peinado incorporados para comprobar de un vistazo su comportamiento. Por otra parte incluía un marco de un tamaño mayor donde se iba construyendo el retrato compuesto con las distintas partes seleccionadas. Finalmente se adjuntaban distintas hojas de acetato y lápices de cera para incorporar a mano tatuajes, cicatrices y otras marcas de la piel. Todas las partes del compuesto final contaban con una numeración con la que obtener un código, que podía ser difundido para reproducir el mismo rostro con otros kits similares, lo que facilitaba su difusión.

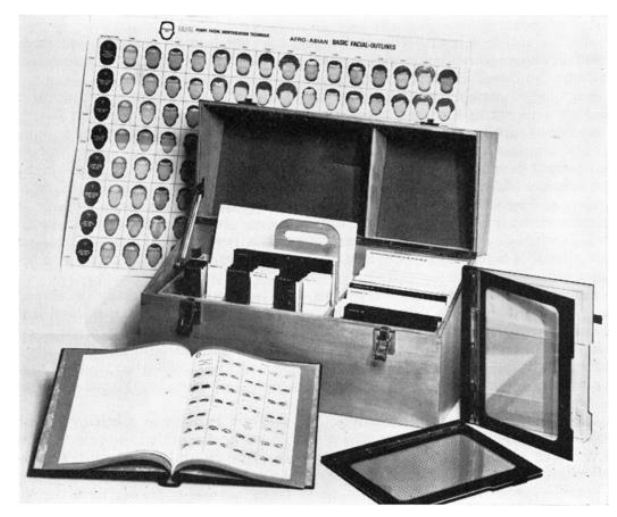

Fig. 10 Photo-FIT kit, Jacques Penry

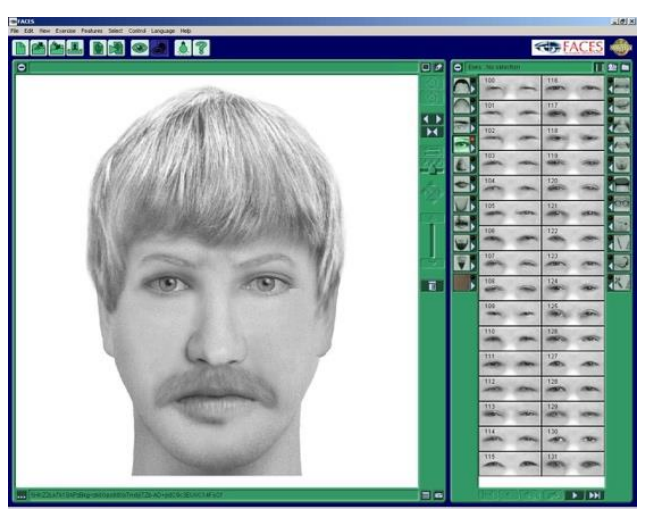

Fig. 11 Interfaz gráfica de Faces

\subsection{Del Photo-FIT al software informático para componer retratos}

A pesar del optimismo de Penry en la eficacia de su método, las limitaciones del sistema Photo-FIT eran evidentes (véase Davies y Valentine, 2007), y él mismo pensaba que quedaba mucho por hacer para que el sistema alcanzase su pleno potencial, imaginando una versión computarizada dotada con una provisión de datos fotográficos faciales de una proyección internacional interrelacionada (Penry 1970). Poco tiempo después su idea se vio en parte materializada y, a petición del Ministerio del Interior Británico, en 1978 el Centro de Diseño Asistido por Ordenador (CADC) desarrolló un prototipo digitalizando los rasgos del Photo-FIT. Este prototipo mejoraba la versión mecánica, por ejemplo igualando el tono de la piel entre los distintos componentes, produciendo un rostro más homogéneo; aunque por otro lado precisaba de una gran computadora para ser utilizado, por lo que todavía hubo que esperar un tiempo a la llegada de los ordenadores de sobremesa y a paquetes gráficos más versátiles y baratos para que aparecieran versiones de software comerciales. De entre los programas informáticos que aparecieron a partir de los años siguientes al prototipo desarrollado por el CADC, destacan principalmente por su uso Mac-a-Mug (desarrollado por Shaharazam en 1986), E-Fit (John Platten, Vision Metric, 1988) e IdentiKit 2000 (Smith \& Wesson, 2000) entre otros tantos; aunque si hubiese que destacar uno que haya traspasado el ámbito forense para introducirse en otros entornos, como el amateur o el educativo, es FACES. The Ultimate Composite Picture (Pierre Côté, IQ Biometrix, 1998). Este software no deja 
de ser una mezcla de distintos sistemas anteriores — tanto mecánicos como computarizados — y sobre todo una actualización híbrida entre los paneles del portrait parlé de Bertillon y el Photo-FIT de Penry. Compuesto por una larga colección de rasgos faciales que se desglosa en 361 modelos de cabello, 63 formas de cabeza, 42 líneas de frente, 410 conjuntos de cejas, 514 pares de ojos, 593 narices, 561 conjuntos de labios, 416 formas de mandíbula, 145 bigotes, 152 barbas, 33 barbas de chivo, 127 pares de gafas, 70 ojos líneas, 147 líneas de la sonrisa, 50 líneas de la boca, y 40 líneas de la barbilla (Wells, Charman y Olson, 2005); el programa destaca por su versatilidad y fácil manejo ya que, como ocurría en el sistema de Penry, las distintas colecciones de rasgos pueden filtrarse por subtipos, lo que hace más fácil acceder al carácter perseguido según la descripción del rostro que se quiera recrear. La principal virtud con respecto a otros sistemas anteriores es la interfaz gráfica (Fig. 11), donde los distintos atributos faciales pueden modificarse en cuanto a escala y posición, además de que, en algunos casos, el sistema permite alargarlos vertical y horizontalmente, lo que proporciona una mayor flexibilidad a la hora de encajar las distintas partes, consiguiendo un rostro más natural.

\subsection{La identificación facial en la práctica artística contemporánea}

La práctica artística contemporánea ha sabido aprovechar algunos de estos métodos para producir distintas series en torno al retrato compuesto fotográfico. ${ }^{1}$ Usando como pretexto el sistema de Penry destaca el proyecto Photofit: Self-Portraits (2007) llevado a cabo por el fotógrafo Giles Revell y el diseñador Matt Willey. Este proyecto producido por el dúo británico para The Guardian Weekend Magazine consiste en una serie de autorretratos (Fig. 12) realizados por medio de dos kits de Photo-FIT - uno masculino y otro femeninoencontrados por los autores en el Museo de la Policía de Kent. Estos kits fueron distribuidos entre un grupo de gente con el propósito de que compusiesen su propio rostro ${ }^{2}$. Este grupo de personas invitadas a participar en el proyecto está formado por — entre otras - un artista forense, un cirujano plástico, un pintor y un fotógrafo de retratos, un modelo y una escritora. La selección de estos invitados no es casual: por una parte supone un guiño a diferentes perfiles profesionales relacionados — desde distintos puntos de vista — con el rostro humano, y por otra parte hay varios individuos seleccionados que presentan una apariencia singular que pone a prueba las limitaciones técnicas del método de Penry. Nos referimos a una serie de personas que, o bien muestran algún tipo de reconstrucción quirúrgica — como un veterano de la Guerra de las Malvinas-, o su estética es particular por alguna cuestión, como un tatuador que muestra tatuajes en distintas partes del rostro o una mujer musulmana que viste con su hijab; en definitiva, individuos que estéticamente escapan del tipo, o por lo menos del tipo criminal imaginado por Penry.

\footnotetext{
${ }^{1}$ Aunque en este artículo nos centramos en trabajos artísticos que se basan en dispositivos fotográficos del ámbito policial para crear retratos compuestos, existen otros ejemplos cuya base la encontramos, por ejemplo, en el portrait parlé de Bertillon, como el trabajo Portraits soufflés, After Alphonse Bertillon (2015) de la artista Isabelle Le Minh, o A war machine (2017) de Sergio Zevallos, recientemente presentado en la documenta 14.

${ }^{2}$ En 2008 este dúo realizó un proyecto similar para la revista canadiense The Walrus titulado Our Faces, Our Selves. En esta ocasión utilizaron una de las últimas versiones del sistema Identi-Kit. Este sistema, anterior al Photo-FIT y que en un principio funcionaba con dibujos de línea de distintos rasgos faciales, se basaba en la superposición de transparencias impresas con las distintas facciones del rostro. Para más información sobre este trabajo véase: <https://thewalrus.ca/our-faces-our-selves/> [Consulta: 14 de septiembre de 2017].
} 
Sospechosos imaginarios: el retrato compuesto en el ámbito artístico por medio de los dispositivos fotográficos policiales. Imaginary suspects: the composite portrait in the artistic field by means of the police photographic devices.

Sin duda, uno de los métodos de composición de retratos que más juego ha dado a la hora de abordar varios proyectos artísticos desde distintas perspectivas, ha sido el software FACES. El primer trabajo al que haremos referencia en base a este programa es un proyecto llevado a cabo por el artista Leandro Berra, titulado Autoportraits robots (2005). El origen de esta serie de trabajos está estrechamente relacionado con la propia biografía de Berra: según cuenta, en tiempos de la dictadura de la Junta Militar en Argentina (1976-1983) cuando era un estudiante que militaba en la resistencia clandestina, un compañero militante suyo llamado Fernando Brodsky fue arrestado por la policía, sin dejar pista alguna sobre su existencia y paradero hasta que en 2002, encontrándose Berra en París donde se había afincado y desarrollado una carrera como artista plástico, recibió un fax que le dejó traspuesto. El comunicado reproducía un documento con la transcripción de un interrogatorio realizado bajo tortura a Brodsky en el que se mencionaba al propio Leandro Berra. En ese momento, ante el estremecimiento de Berra por el sufrimiento que tuvo que padecer su compañero, sintió la necesidad de recrear el retrato de su amigo a modo de homenaje y decidió hacerlo a través de un retrato-robot, en un intento por invertir el sentido de este método de identificación policial que le "asistiría en su reaparición simbólica” (Fontcuberta, 2010). A través de la Gendarmería científica de París que le formó para usar el software FACES, Berra reconstruyó el rostro de Brodsky de memoria, aunque con unos resultados al parecer bastante decepcionantes, al comprobar que por muy clara que tengamos la imagen mental de una persona, darle una apariencia física convincente a partir de "sus componentes fraccionados e individualizados" (Fontcuberta, 2010) resulta prácticamente imposible. A partir de esta imposibilidad y bajo la premisa — que no difiere mucho del trabajo comentado anteriormente de Revell y Willey - de ofrecer a distintos participantes voluntarios la oportunidad de realizar su propio autorretrato por medio de FACES, sin la ayuda de una fotografía de ellos mismos o espejo alguno, Berra recopiló unos 80 autorretratos robots para posteriormente yuxtaponer cada imagen compuesta junto al correspondiente retrato fotográfico del autor participante (Fig. 13). Con este proyecto no solamente se pone en evidencia la capacidad de recrear un rostro de memoria, sino también las restricciones del propio software, que a pesar de contar con una amplia colección de facciones no es capaz de reproducir — con total similitud — las particularidades individuales de cada rostro.

Hasta ahora, las series fotográficas que hemos revisado tienen su origen en la experiencia personal, imaginando nuevas identidades ficticias a partir de la superposición de retratos ya existentes (Ruff y Mitscher), o recreando el propio rostro de uno mismo mezclando distintos rasgos de un archivo facial (Revell y Willey o Leandro Berra), pero en cualquier caso, prescindiendo todos ellos de descripciones verbales para la combinación del retrato compuesto. En el ámbito policial forense, el testimonio de un testigo es vital para poder generar una imagen cercana a la apariencia real de un sospechoso, y sin duda los distintos dispositivos de imagen dentro de este ámbito han perseguido este objetivo, asociando distintos calificativos verbales a los tipos de rasgos faciales, configurando una taxonomía iniciada con Bertillon. El siguiente trabajo se fundamenta precisamente en la recreación de un rostro a partir de una descripción. Se trata del trabajo The composites, realizado por el artista digital y cineasta Brian Joseph Davis. Desde 2012, Davis lleva recreando — por medio del programa FACESretratos compuestos de personajes literarios basándose en sus propias historias y descripciones (Fig. 14). El propósito en este caso se basa en recrear la imagen física — como si de una persona real se tratase- de un 
personaje de ficción, a partir de la imagen mental que se construye por medio del desarrollo de la novela que da cuerpo al propio personaje. Y qué mejor descripción que una en la que además de los detalles físicos se nos revela la parte psicológica del individuo, su modo de actuar, parte de su biografía... Personajes como Tom Ripley (El talento de Mr. Ripley de Patricia Highsmith), Rachael Rosen (¿Sueñan los androides con ovejas eléctricas? de Philip K. Dick), Erik (El fantasma de la ópera de Gaston Leroux), Julia (1984 de George Orwell), Ignatius J. Reilly (La conjura de los necios de John Kennedy Toole) o Humbert Humbert (Lolita de Vladimir Nabokov) entre otros muchos. El resultado final son una serie de inquietantes rostros que deambulan entre lo real y lo ficticio con una apariencia inexpresiva a veces, pero cargados sin duda, de una gran personalidad.

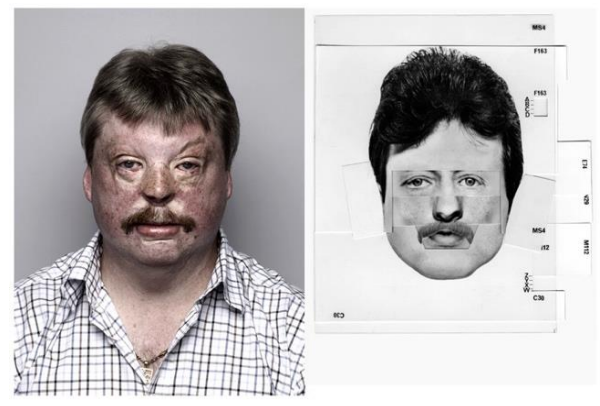

Fig. 12 Photofit: Self-Portraits, Revell y Willey

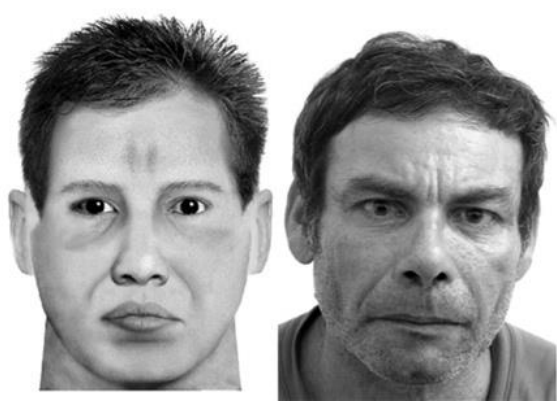

Fig. 13 Autoportraits Robots, Leandro Berra

Por último nos resulta pertinente incluir un trabajo que aprovecha el uso de software específico para recrear un rostro junto a otros mecanismos no fotográficos propios del aparato de identificación policial, para desarrollar un proyecto artístico articulado a través de ciertos parámetros en torno a la construcción de la identidad. Se trata del proyecto Dominique Lambert (2004-2010) de la artista francesa Stéphanie Solinas. El proyecto se genera en distintas fases y parte del nombre Dominique, que se corresponde con el nombre sin género más común en Francia. Además Dominique es el vigésimo séptimo nombre más popular en general, siendo el vigésimo séptimo apellido Lambert. A partir de esta premisa, la autora del proyecto buscó en la guía telefónica todas las personas identificadas con el nombre de Dominique Lambert para hacerles llegar un portrait chinois $^{3}$ (retrato chino) y un test de personalidad, confeccionados a partir del estudio caracterológico del propio nombre Dominique. A partir de las respuestas de los veinte retratos chinos obtenidos, se elaboró un retrato escrito con la ayuda de un comité experto - formado por un psicólogo, un estadístico, un inspector de policía, un abogado y un consultor de identidad judicial- y con estas descripciones un pintor realizó distintos retratos dibujados, al estilo de los retratos de identificación policiales. La siguiente fase consistió en entregar estos retratos a un investigador de la Policía de la Identidad Judicial, que a través de un software de identificación facial trasladó estos dibujos a retratos robot (Fig. 15). El proyecto se cierra con la búsqueda de modelos que presentasen un parecido evidente a los retratos robot para ser fotografiados.

\footnotetext{
${ }^{3}$ Un retrato chino es un juego literario en el que se trata de identificar ciertos aspectos de la personalidad de un individuo, gustos o preferencias personales a través de un cuestionario basado en la identificación con animales, objetos y otros elementos.
} 
Sospechosos imaginarios: el retrato compuesto en el ámbito artístico por medio de los dispositivos fotográficos policiales. Imaginary suspects: the composite portrait in the artistic field by means of the police photographic devices.

El uso del software de identificación facial utilizado en este proyecto — del que no podemos precisar su tipono es lo más destacado, sino una parte más dentro de su desarrollo, basado en todo un juego de descripciones, construcción de identidades e identificación, que sintetiza de un modo capaz varias de las cuestiones que hemos tratado anteriormente. Es por ello que los retratos fotográficos resultantes podríamos entenderlos como retratos compuestos, en el sentido de que su apariencia e identidad ha sido construida a partir de distintos elementos que la configuran desde lo real y lo imaginario.

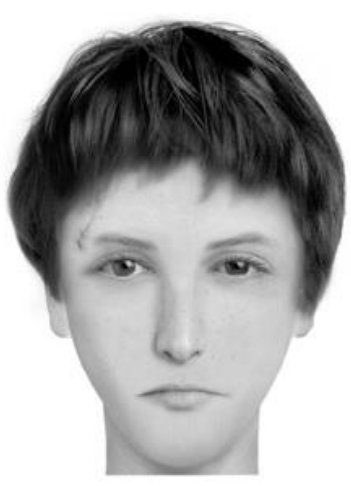

Fig. 14 The composites, Brian Joseph Davis

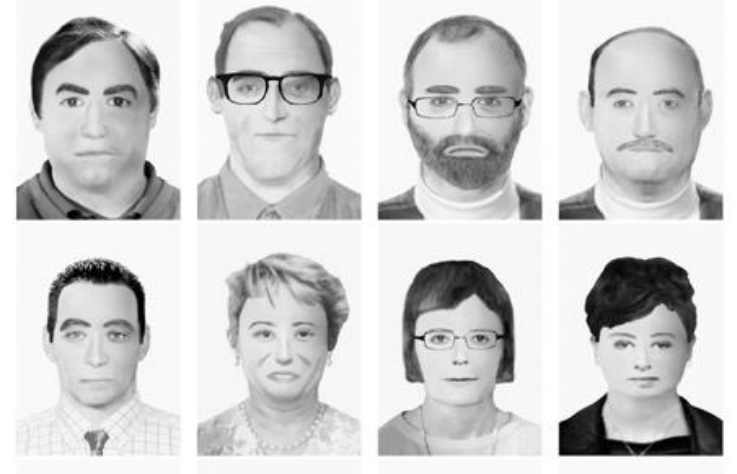

Fig. 15 Dominique Lambert, Stéphanie Solinas

\section{Conclusiones}

Paralelamente al desarrollo histórico de la fotografía judicial - y junto a esta de los dispositivos fotográficos policiales - surgida en el último cuarto del siglo XIX, se efectuó la construcción de un basto archivo fotográfico en torno al rostro humano que permitió su tipificación y clasificación. Este gran archivo no surge solamente gracias al desarrollo de los aparatos fotográficos, sino al hecho de que la cámara formó parte de un sistema más amplio en pleno auge, "un sistema de trabajo policial, cada vez más profesionalizado y tecnológico" (Sekula, 2003). El archivo se constituyó como un mecanismo que permitió la comparación entre sus elementos gracias a la precisión métrica de la cámara, abriendo las puertas a las aplicaciones estadísticas a partir de la imagen fotográfica. A su vez el retrato fotográfico se fundamentó en una doble dirección, como "un sistema de representación capaz de funcionar tanto honoríficamente como represivamente" (Sekula, 2003), y estableciendo de algún modo "el terreno del otro" (Sekula, 2003), donde se encuadraría al criminal.

Mientras que Bertillon se centraba en lo particular del individuo criminal para identificarlo, Galton no buscaba tanto al criminal sino "al hombre propenso a cometer un crimen" (Galton, 2006). En ambos casos, la fotografía se convertía en una prueba particular; si en el primero esta verdad visual se refuerza con el plano verbal y el antropométrico, en el segundo es fruto de la magia óptica y su poder para revelar fenómenos que el ojo no es capaz de visualizar por si mismo. Nos referimos con esta idea a que por muy irreales que sean los retratos compuestos - tanto promediados como seccionados - en el fondo están constituidos por fotografías, lo que le 
otorga un cierto carácter verosímil y objetivo, tanto en los ejercicios ópticos decimonónicos como en todos los compuestos surgidos posteriormente.

Como hemos visto, el empleo de los dispositivos fotográficos policiales en la práctica artística aporta una carga simbólica al discurso final del trabajo artístico, que viene dada por la propia condición de estos mecanismos, cuyo fin último es el de la reconstrucción de un retrato que permita la captura de un criminal o sospechoso dentro del ámbito judicial y policial. El empleo de estos aparatos casi siempre se produce desde dos estrategias: o bien desde un punto de vista instrumental, aprovechando las características potenciales de cada método; o en otras ocasiones desde una perspectiva crítica, evidenciando los límites y carencias de algunos procedimientos. Desde esta posición, existen numerosos estudios que ponen en tela de juicio la capacidad de reconstrucción de un rostro particular a partir de una descripción testimonial, demostrando la baja posibilidad de éxito y lo arbitrario que pueden resultar determinados procedimientos de identificación, algunos todavía vigentes. Esta incapacidad se produce — como ya hemos expuesto - por la insuficiencia de datos fisonómicos que normalmente aparecen en el relato del testigo y por la propia arquitectura de los aparatos de identificación.

\section{Referencias}

ADLER, D. (2016). “The Apparatus: On the Photography of Thomas Ruff”, Art Journal, 75:2, pp 66-87.

BERTILLON, A. (1893). Identification anthropométrique. Instructions signalétiques. Melun: Imprimerie administrative.

BLANK, G. y RUFF, T. (2004) “Gil Blank and Thomas Ruff in Conversation”, Influence, Issue 2, pp. 48- 59.

DAVIES, G. M. y VALENTINE, T. (2007). Facial Composites: Forensic Utility and Psychological Research $<$ https://www.researchgate.net/publication/253189498_Facial_Composites_Forensic_Utility_and_Psychological_Research> [Consulta: 6 de septiembre de 2017].

DUNCAN, F. y LAUGHERY, K. (1977). The Minolta Montage Synthesizer as a facial image generating device (Mug File Project [Report No. HHMUG-4]). Houston: University of Houston. $<$ https://www.ncjrs.gov/App/publications/Abstract.aspx?id=47587> [Consulta: 22 de agosto de 2017].

ERFOLG MIT FRATZEN (24 de julio de 1978). Der Spiegel, 30/1978, pp. 48-49. <http://www.spiegel.de/spiegel/print/d40694081.html> [Consulta: 31 de agosto de 2017].

FONTCUBERTA, J. (2010). La cámara de Pandora: La fotografi@ después de la fotografía. Barcelona : Gustavo Gili.

GALTON, F. (2006). "Retratos compuestos" en Naranjo, J. (ed.). Fotografía, antropología y colonialismo (1845-2006). Barcelona: Gustavo Gili.

HOPPER, W. R. (1973). Photo-FIT - The Penry Facial Identification Technique. Journal of the Forensic Science Society, Volume 13, Issue 2, April 1973, pp 77-82.

MAXWELL, A. (2010). Picture imperfect: Photography and Eugenics, 1870-1940. Brighton: Sussex Academic Press.

SEKULA, A. (2003). "El cuerpo y el archivo" en Picazo, G. y Ribalta, J. (eds.). Indiferencia y singularidad. La fotografia en el pensamiento artístico contemporáneo. Barcelona: Gustavo Gili.

WELLS, G.L., CHARMAN, S.D., Y OLSON, E.A. (2005). Building face composites can harm line-up identification performance. Journal of Experimental Psychology: Applied, 11, pp. 147-157. 